\title{
The Application of SWMM Model in the Urban Planning Study on Sponge City
}

\author{
Zhang Bin ${ }^{1,}$, , Gu Jin ${ }^{2}$, Shi Xiangrong ${ }^{3}$, Weng Xiaohua ${ }^{3}$, Zhong Hua ${ }^{4}$ \\ ${ }^{1}$ Jiangsu Institute of Urban Planning and Design, Nanjing, China \\ ${ }^{2}$ Quzhou City Water Conservancy Bureau, Quzhou, China \\ ${ }^{3}$ Quzhou Water Resource \& Hydropower Suvey \& Design Co., Ltd, Quzhou, China \\ ${ }^{4}$ Nanjing Hydraulic Research Institute, Nanjing, China
}

\section{Email address:}

plozhangbin@163.com (Zhang Bin), qzfb@163.com (Gu Jin), 978585214@qq.com (Shi Xiangrong), 43843462@qq.com (Weng Xiaohua), hzhong@nhri.cn (Zhong Hua)

\section{To cite this article:}

Zhang Bin, Gu Jin, Shi Xiangrong, Weng Xiaohua, Zhong Hua. The Application of SWMM Model in the Urban Planning Study on Sponge City. Earth Sciences. Vol. 4, No. 5, 2015, pp. 205-210. doi: 10.11648/j.earth.20150405.17

\begin{abstract}
With urbanization, the proportion of land surface hardening increases, urban stormwater issues have become increasingly prominent. Based on "sponge city" by China, Quzhou old town used infiltration trenchs, permeable pavements, and rain gardens taking the total amount of runoff and peak control as goal in this paper. The paper established city rainwater model of the study area with SWMM and simulated every LID facility using LID module in the model.The research shows that infiltration trenchs had not only best effects on controlling node flooding, but also strongest control on reducing peak flow and delaying time of appearance of flood peak. The control of total runoff valume with permeable pavements was the most effective way.
\end{abstract}

Keywords: SWMM Model, Sponge City, Low Impact Development, Storm Water Regulation

\section{SWMM模型在海绵城市规划研究中应用}

\author{
张森 ${ }^{1, *}$, 顾锦 ${ }^{2}$, 石向荣 ${ }^{3}$, 翁小华 ${ }^{3}, \mathrm{c}^{\text {华 }}{ }^{4}$ \\ ${ }^{1}$ 江苏省城市规划设计研究院, 南京, 中国 \\ 2忂州市水利局, 忂州, 中国 \\ 微州市水利水电勘测设计有限公司, 微州, 中国 \\ ${ }^{4}$ 南京水利科学研究院, 南京, 中国 \\ 邮箱 \\ plozhangbin@163.com(张涁), qzfb@163.com(顾锦), 978585214@qq.com(石向荣), 43843462@qq.com(翁小华), \\ hzhong@nhri.cn(钟华)
}

\begin{abstract}
摘要：随着城市化发展，下垫面硬化比例逐渐增大，城市雨洪问题日益突出。本文结合中国 “海绵城市” 提出背景， 以径流总量和峰值控制为目标, 对瞧州市老城区采用渗透沟渠、渗透铺装、雨水花园等低影响措施。采用SWMM模型建 立研究区城市雨洪模型, 利用模型中低影响开发模块对布设的各项LID措施进行模拟。研究表明, 渗透沟渠措施不仅对 节点积水改善效果最好, 而且对径流洪峰削减和延缓峰现时间作用最明显, 渗透铺装措施对排水口径流总量削减作用 最强。
\end{abstract}

关键词: SWMM模型, 海绵城市, 低影响开发, 雨洪调蓄 


\section{1. 引言}

伴随着中国快速的城市化进程, 城市规模扩大, 水面 率下降, 人口不断增加, 水资源越发短缺; 城市地面结构 发生了改变, 不透水面积比例大大增加, 城区水文水力特 性明显改变, 城市排水防涝压力增大; 与此同时污染物在 城市水体的粗放式排入方式，水体污染也越来越严重。鉴 于城市化的不断探索过程中, 面对日益突出的水生态环境 问题 [1-3], 中国政府提出要建设自然积存、自然渗透、 自然净化的 “海绵城市” 的伟大构想, 海绵城市的核心目 标是维持城市开发建设前后水文特征不变 [4-5], 具体的 说就是依靠低影响开发 (Low Impact Development) 的先 进理念, 在城市开发建设过程中采用源头削减、中途传输、 末端调蓄等多种手段, 通过渗、滞、蓄、净、用、排等多 种技术, 实现城市良性水文循环, 提高对径流雨水的渗透、 调蓄、净化、利用和排放能力, 维持或恢复城市的 “海绵” 功能。为了更好进行海绵城市建设, 中国住建部组织编写 了《海绵城市建设技术指南一低影响开发雨水系统构建》, 提出了径流总量控制、径流峰值控制、径流污染控制等目 标, 如何评价各种雨洪控制措施的调蓄效果, 为海绵城市 规划建设提供技术支撑非常重要。

本文选取倠州市老城区部分区域作为研究对象, 以径 流总量控制和径流峰值控制为目标确定渗透沟渠、透水铺 装、雨水花园等低影响设施规模, 利用SWMM模型针对研究 区域水文水力特性进行概化, 并模拟计算三种低影响开发 措施对研究区不同重现期暴雨洪水的控制效果, 通过对比 分析, 探索对径流总量控制、径流峰值控制目标实现最有 效的实施方案, 为海绵城市规划建设提供技术参考和依据。

\section{SWMM模型LID模块}

\section{1 . 模型介绍}

雨洪管理模型 (SWMM) 是一个动态降雨--径流演算模 拟模型, 主要用于城市地区径流水量和水质的单一事件 或者长期 (连续) 模拟。最新版本5.1中LID模块功能更加 完善, 可模拟生物滞留网格（Bio-Retention Ce11）、雨 水花园（Rain Garden）、绿色屋顶（Green Roof）、渗 透沟渠 (Infiltration Trench) 、透水铺装 (Permeable Pavement)、雨水桶 (Rain Barre1)、植草沟 (Vegetative Swale) 等多种低影响开发措施, 通过对滞蓄、下渗和蒸 发等水文过程的模拟, 结合SWMM模型的水力计算模块, 实 现LID措施对场地径流量、峰值流量、污染物浓度控制效 果的模拟。很多文献利用水力模型模拟, 对不同LID单元 的雨洪控制效果进行了探索和研究 [6-9]。SWMM模型可以 较好模拟海绵城市中低影响开发措施雨洪调蓄效果, 为城 市规划建设提供技术参考。

\section{2. LID模拟原理及布置方式}

每个LID单元在SWMM模型中通过表面层、路面层、土 壤层、蓄水层等不同坚向层的组合来表示, 不同坚向层之
间进行水量平衡计算。SWMM模型提供两种LID布设方式, 一种是在子汇水去内放置一种或者多种LID单元, 取代等 量的子汇水面积内非LID面积; 另外一种是将整个子汇水 区作为一个LID单元考虑, 即总体上采用单一的LID实践。

第一种方法允许同一子汇水区内包含多个LID单元组 合, LID组合子汇水单元与非LID子汇水单元共同组成汇水 区, 这种方法中LID组合是并行作用而非串联作用（即一 个LID控制的出流成为另一LID的进流）。采用这种方法布 置LID措施后, 考虑到原有子汇水区一部分汇水面积被LID 单元取代, 原子汇水区不渗透面积百分比和漫流宽度属性 需要调整（如图1所示）。

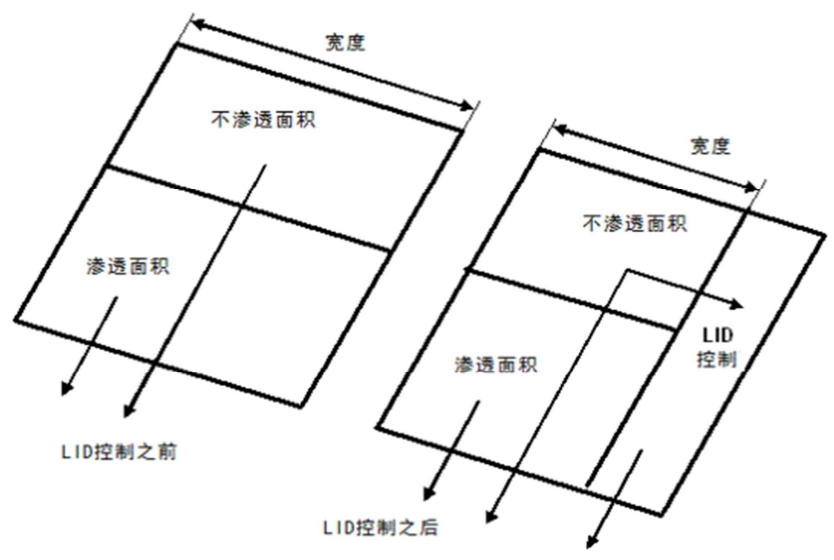

图1 子汇水区LID布设前后对比图。

第二种方法允许不同LID单元进行串联作用, 也允许 来自不同子水水区的径流进入LID子汇水面积。在进行LID 措施设置时注意单个LID单元面积超过子汇水区面积时, 对子汇水区不透水性、漫流宽度和面积值等参数进行调整。 因为当LID单元被定义为占据整个子汇水区时, 赋给子汇 水区原有参数 (例如不渗透性、坡度、粗粘度等) 将被LID 单元参数重载。

\section{3. 研究区水力模型构建}

\section{1. 研究区概况}

浙江省瞿州市地处中国东南部, 属亚热带季风气候区, 降水丰沛, 多年平均降雨量 $1700 \mathrm{~mm}$ 左右。研究区地处瞿州 市中心城区沿江地带, 近年来夏季台风和大暴雨频发, 市 政管网排水不畅, 加之城市排水系统受到临江高水位顶托 作用, 内涝问题日益突出。研究区位于老城区, 原有管道 设计排水标准多为 $0.5^{\sim} 1$ 年一遇, 排水能力不足。研究区 总面积 $197.5 \mathrm{hm}^{2}$, 区内地面情况复杂, 包括交通道路、居 住区、商业区、工业、绿地等, 根据《室外排水设计规范 （GB50014-2006）》（2014 修订版）确定的雨水径流系 数参考值, 加权计算各类用地的综合径流系数, 城市用地 分类面积及综合径流系数参考值见表1。

考虑经济社会发展、城市发展空间、排水防涝需求等 因素, 又由于径流污染控制目标在实践中一般转化为年径 流总量控制目标, 所以选择径流总量控制目标和径流峰值 
控制目标作为研究区域探索海绵城市建设的控制目标。依 照《指南》, 研究区年径流总量控制率分区属于III区 $(75 \%$ $\leqslant$ 年径流总量控制率 $\leqslant 85 \%$ ），选定年径流总量控制率为 80\%, 参照长期降雨规律相似的其他城市的设计暴雨值, 研究区 $80 \%$ 年径流控制率对应的设计暴雨值（日雨量）为 24. $9 \mathrm{~mm}$ 。

表1 研究区城市用地分类汇总表。

\begin{tabular}{lll}
\hline 用地分类 & 用地面积 $\left(\mathrm{hm}^{2}\right)$ & 径流系数参考值 \\
\hline 居住区 & 26.2 & 0.7 \\
公共管理与公共服务区 & 3.6 & 0.8 \\
商业服务业区 & 11.2 & 0.8 \\
工业区 & 82.2 & 0.65 \\
物流仓储区 & 5.7 & 0.7 \\
交通道路 & 30.5 & 0.9 \\
公用设施 & 1.5 & 0.7 \\
绿地 & 36.4 & 0.15 \\
合计 & 197.5 & 0.62 \\
\hline
\end{tabular}

根据研究区域年径流总量控制要求, 采用单位面积控 制容积方法计算LID设施规模, 公式如下:

$$
V_{S}=H^{*} \varphi
$$

式中: $V_{S}$ 一一单位面积设计调蓄量 $(\mathrm{mm}), H-$ 设计降雨量 $(\mathrm{mm}), \varphi$-一综合雨量径流系数。由公式 (1) 可计算, 研究区域单位面积设计调蓄量为 $15.44 \mathrm{~mm}$ 。

\section{2. 模型概化及主要参数设置}

根据研究区水文水力特性, 综合考虑管网、河道、道 路、区域防洪排涝布局等因素, 将研究区划分为 48 个子水 区，透水面积 $72.3 \mathrm{hm}^{2}$ ，占总面积 $36.6 \%$; 不透水面积
125. $2 \mathrm{hm}^{2}$, 占总面积 $63.4 \%$ 。概化排水主干管道 46 条, 总 长度 $3119 \mathrm{~m}$, 管径为 $600 \mathrm{~mm}^{2} 1200 \mathrm{~mm}$ 不等; 概化汇接点 35 个, 排水口19个。研究区域模型概化情况见图2。

模型参数的初值主要参照相关文献 [10] 和SWMM模型 用户手册 [11]进行选取, 然后通过多次分析率定后选定合 适的参数。主要参数包括子汇水区不透水面积比例、地表 洼蓄量、下渗参数、曼宁系数等。以子汇水区内不同地块 类型的综合径流系数参考值, 加权计算各子汇水区不透水 面积比例; 分析研究区地表植被覆盖情况, 透水区洼蓄量 取 $8 \mathrm{~mm}$, 不透水区洼蓄量取 $2 \mathrm{~mm}$; 采用Horton下渗模型模拟 降雨入渗过程, 最大下渗率取 $35.2 \mathrm{~mm} / \mathrm{h}$, 稳定下渗率取 $2.1 \mathrm{~mm} / \mathrm{h}$, 衰减常数取 $3 \mathrm{~h}^{-1}$ 。根据研究区下垫面情况, 不透 水区和透水区曼宁系数分别取 0.015 和取 0.2 。

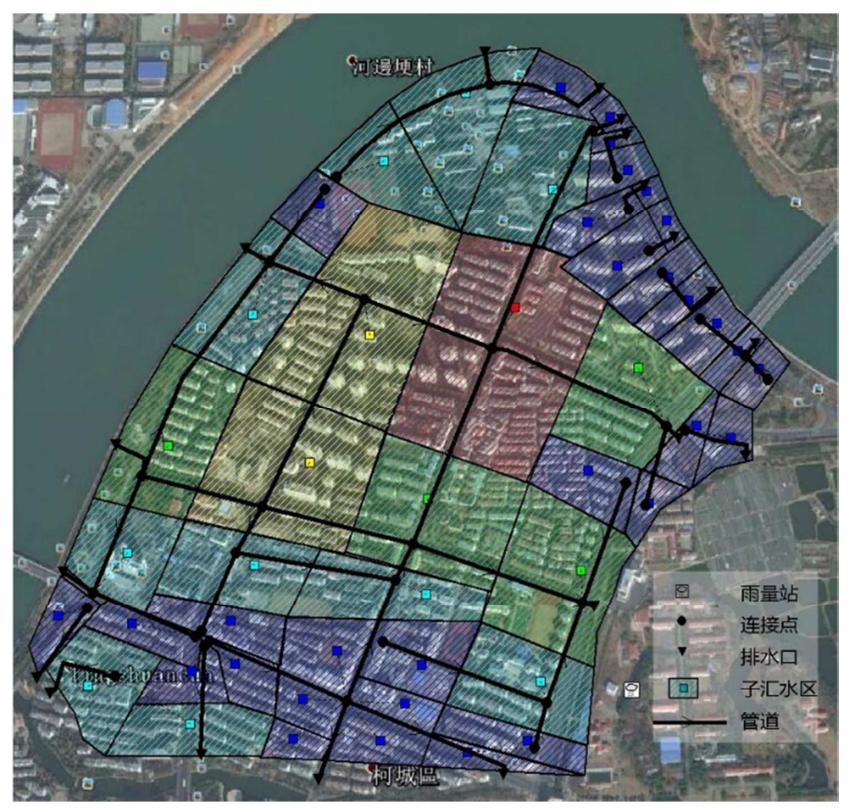

图2 研究区域概化图。

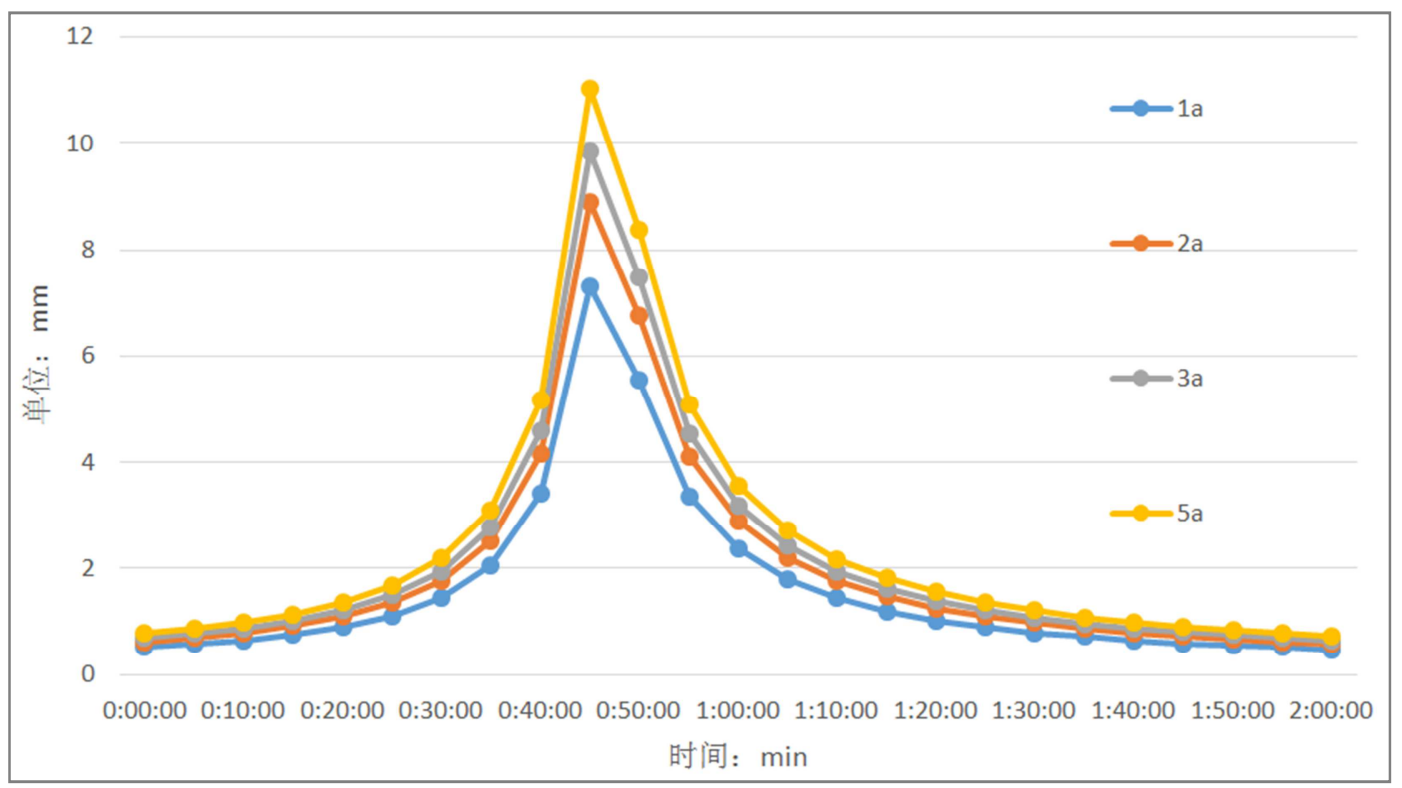

图3 不同重现期设计暴雨过程图。 


\section{3. 设计暴雨计算}

忂州市暴雨强度公式采用年最大值法选样, 具体形式 如下:

$$
i=\frac{16.272+11.884 \lg P}{(t+14.823)^{0.792}}
$$

式中: $i$ 一一设计暴雨强度 $(\mathrm{mm} / \mathrm{min}), t$ 一一降雨 历时 (min) , $P$ - 一设计重现期 (a)。根据暴雨强度公 式可以计算出年径流总量控制率 $80 \%$ 对应的的设计日雨量 值相当于 1 年一遇 30 分钟雨量。

形成暴雨径流过程的最主要降雨因素是暴雨的平均 强度、暴雨最强时段的强度, 以及暴雨强度的过程。暴雨 强度公式仅仅表示了平均强度与最强时段的规律, 并不能 描绘暴雨强度的过程, 而不同的强度过程, 对径流曲线与 调蓄计算均有重要的影响。本文选取芝加哥雨型来描述暴 雨强度过程, 城市雨峰系数一般取值 $0.3^{\sim} 0.5$, 依据经验 本次设计暴雨计算取值 0.4 。根据睢州市的暴雨强度公式 和芝加哥雨型计算公式 [12], 计算出重现期分别为 $1 \mathrm{a}, 2 \mathrm{a}$, $3 \mathrm{a}, 5 \mathrm{a}$ 下的 2 小时 5 分钟步长降雨量曲线图, 如图3所示。 为了考虑降雨能够充分产流, 模型模拟时间延长 2 小时。

\section{4. 模拟结果及分析}

\section{1. LID方案及布设}

表2 LID措施主要参数设置表。

\begin{tabular}{llllll}
\hline LID坚向层 & 表面层 & \multicolumn{2}{l}{ 土壤层/路面 } & 蓄水层 & \\
\cline { 2 - 6 } 主要参数 & 曼宁系数 & 厚度 $(\mathrm{mm})$ & 孔隙比 & 暻度 $(\mathrm{mm})$ & 孔隙比 \\
\hline 透水铺装 & 0.015 & 60 & 0.25 & 160 & 0.4 \\
渗透沟渠 & 0.2 & & & 200 & 0.6 \\
雨水花园 & 0.25 & 180 & 0.5 & & \\
\hline
\end{tabular}

本文选取透水铺装、渗透沟渠、雨水花园等三种LID 措施的作为雨洪调蓄模拟对象。根据年径流总量控制目标 确定的单位面积调蓄容积, 确定研究区域LID调蓄设施的 规模和布置面积。LID措施主要参数设置见表 2 。

（1）透水铺装与传统地面硬化铺层相比, 大大降低 了不透水面积比例, 并且使暴雨径流能够快速深入到下面 蓄水土壤层, 从而达到降低地表径流量、滞留雨洪的目的。 主要用于硬化地面改造和停车场的地面铺设。

（2）渗透沟渠设置在道路两侧，可以快速收集和输 送道路雨水, 与道路排水系统相互补充既能够快速排出道 路积水又能蓄留雨水, 减缓管网排水压力。
（3）雨水花园布设在广场、休息花园等公共活动空 间中，不仅能够满足空间绿化需求，也能吸收储存部分雨 水量。

（4）结合研究区实际情况，有选择的在条件允许的 子汇水区布设透水铺装、渗透沟渠、雨水花园等LID设施, 本文为了研究分析三种LID措施的雨洪控制效果, 假设每 个子汇水区分别布置透水铺装、渗透沟渠、雨水花园等措 施中的一种，每种LID铺设面积为总面积的 $10 \%$ 。

\section{2. 方案模拟及分析}

本文利用SWMM模型，模拟计算研究区在 $1 a 、 2 a 、 3 a$ 、 $5 \mathrm{a}$ 等不同重现期下，现状和采用每种LID措施后城区节点 溢流和排水区洪流情况。以沿江排水口025（承担8个子汇 水区排水任务, 总汇水面积 $57.86 \mathrm{hm}^{2}$ ) 为例, 对比分析各 个方案的雨洪控制效果。

（1）积水控制

基于SWMM模型运行结果, 对各方案在不同重现期下研 究区积水情况进行分析, 见表 3 。分析模拟结果发现, 总 的来说, 渗透沟渠在减少积水节点、降低积水时间、排除 积水总量等方面效果最好; 透水铺装只能通过减少积水时 间和积水量改善积水情况, 并没有减少积水节个数; 雨水 花园对节点积水的调蓄效果介于渗透沟渠渠和透水铺装 两种措施之间。在减少积水时间方面, 与其他两种措施相 比, 渗透沟渠渠措施在低重现期时（2年一遇以下）表现 更为明显, 见图 4; 三种LID措施在消减积水总量方面都有 一定效果, 渗透沟渠和雨水花园效果更好, 随着重现期增 大，各项措施对积水量的消减作用减弱，见图5。

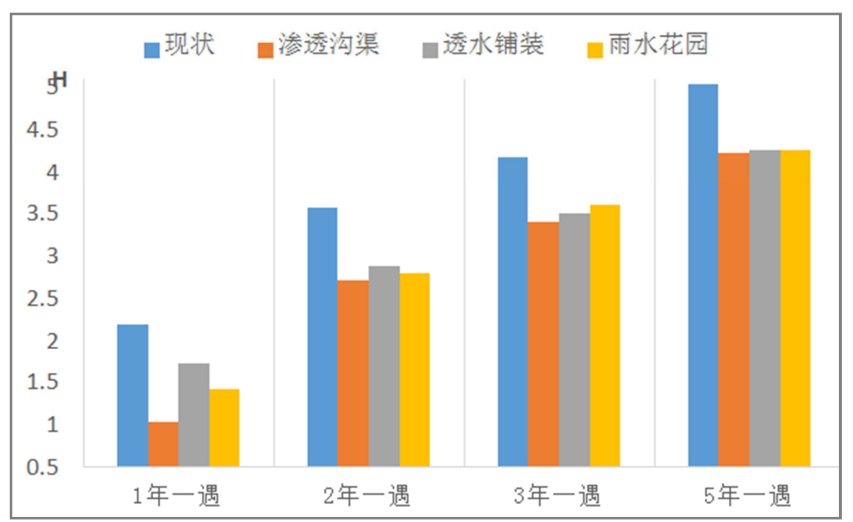

图4 不同重现期各方案积水时间对比图。

表3 不同重现期各方案积水情况表。

\begin{tabular}{|c|c|c|c|c|c|c|c|c|c|c|c|c|}
\hline 重 & 现状 & & & 渗透沟讶 & & & 透水铺装 & & & 雨水花园 & & \\
\hline 现 & $\begin{array}{l}\text { 积 水 节 } \\
\text { 点数 }\end{array}$ & $\begin{array}{l}\text { 累计积水 } \\
\text { 时间 (h) }\end{array}$ & $\begin{array}{r}\text { 总积水量 } \\
\left(\times 10^{6} \mathrm{~L}\right)\end{array}$ & $\begin{array}{l}\text { 积 水节 } \\
\text { 点数 }\end{array}$ & $\begin{array}{l}\text { 累计积水 } \\
\text { 时间 }(\mathrm{h})\end{array}$ & $\begin{array}{c}\text { 总积 水量 } \\
\left(\times 10^{6} \mathrm{~L}\right)\end{array}$ & $\begin{array}{l}\text { 积 水 节 } \\
\text { 点数 }\end{array}$ & $\begin{array}{l}\text { 累计积水 } \\
\text { 时间 (h) }\end{array}$ & $\begin{array}{r}\text { 总积水量 } \\
\left(\times 10^{6} \mathrm{~L}\right)\end{array}$ & $\begin{array}{l}\text { 积水节 } \\
\text { 点数 }\end{array}$ & $\begin{array}{l}\text { 累计积水 } \\
\text { 时间 (h) }\end{array}$ & $\begin{array}{c}\text { 总积 水量 } \\
\left(\times 10^{6} \mathrm{~L}\right)\end{array}$ \\
\hline 1a & 5 & 2. 19 & 1.676 & 4 & 1.04 & 0.994 & 5 & 1.73 & 1.329 & 5 & 1. 42 & 1.11 \\
\hline $2 \mathrm{a}$ & 7 & 3.57 & 3.223 & 5 & 2. 72 & 2. 047 & 7 & 2. 88 & 2. 621 & 6 & 2.8 & 2. 21 \\
\hline $3 a$ & 8 & 4. 186 & 4. 207 & 7 & 3.41 & 2. 895 & 8 & 3. 51 & 3. 522 & 7 & 3. 6 & 3.06 \\
\hline $5 a$ & 13 & 5. 04 & 5. 197 & 7 & 4. 23 & 4. 102 & 13 & 4. 26 & 4.766 & 9 & 4. 27 & 4. 257 \\
\hline
\end{tabular}




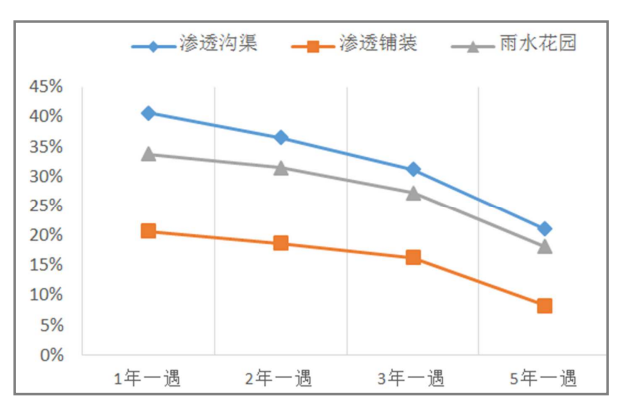

图5 不同重现期各方案积水量削减百分比趋势图。
（2）径流控制

不同重现期各方案排水口025的径流峰值模拟结果见 表4。分析模拟结果可知, 三种LID措施都能延迟峰现时间, 渗渠作用最强, 而渗透铺装作用最弱。渗渠和雨水花园对 洪峰削弱作用较强, 渗透铺装对洪峰削减作用很弱, 不同 重现前期下洪峰流量削减率相差不大，见图6。而在径流 总量控制方面, 三种措施的削减强度关系为: 渗透铺装> 雨水花园>渗渠, 超过 2 年一遇重现期时, 各措施对径流总 量的削减率保持稳定, 见图7。

表4 洪流模拟结果表。

\begin{tabular}{|c|c|c|c|c|c|c|c|c|}
\hline \multirow{2}{*}{ 重现期 } & \multicolumn{2}{|l|}{ 现状 } & \multicolumn{2}{|l|}{ 渗透沟渠 } & \multicolumn{2}{|l|}{ 透水铺装 } & \multicolumn{2}{|l|}{ 雨水花园 } \\
\hline & 洪峰流量 $\left(\mathrm{m}^{3} / \mathrm{s}\right)$ & 峰现时间 & 洪峰流量 $\left(\mathrm{m}^{3} / \mathrm{s}\right)$ & 峰现时间 & 洪峰流量 $\left(\mathrm{m}^{3} / \mathrm{s}\right)$ & 峰现时间 & 洪峰流量 $\left(\mathrm{m}^{3} / \mathrm{s}\right)$ & 峰现时间 \\
\hline 1a & 2.846 & $1: 10$ & 2.445 & $1: 13$ & 2.815 & $1: 11$ & 2.541 & $1: 12$ \\
\hline $2 \mathrm{a}$ & 3.373 & $1: 05$ & 2.937 & $1: 10$ & 3.354 & $1: 07$ & 2.991 & $1: 09$ \\
\hline $3 a$ & 3.766 & $1: 02$ & 3. 197 & $1: 07$ & 3.692 & $1: 03$ & 3.261 & $1: 06$ \\
\hline $5 a$ & 4. 173 & $1: 01$ & 3.569 & $1: 04$ & 4. 088 & $1: 01$ & 3.634 & $1: 03$ \\
\hline
\end{tabular}

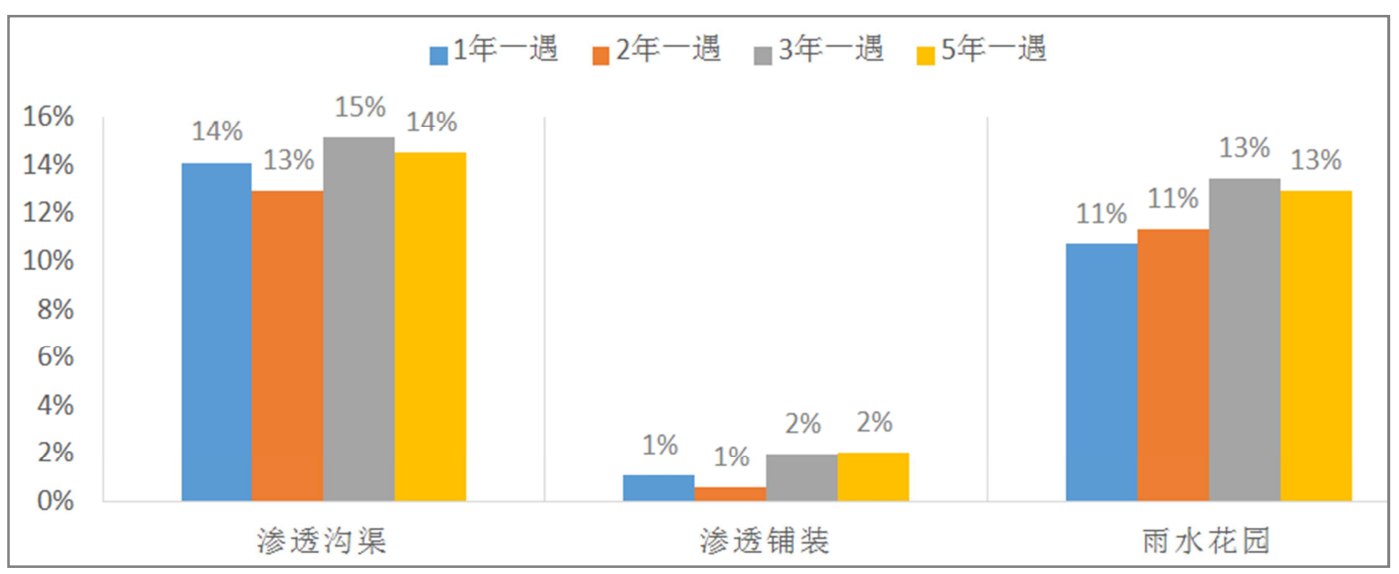

图6 不同重现期各方案洪峰流量削减率对比图。

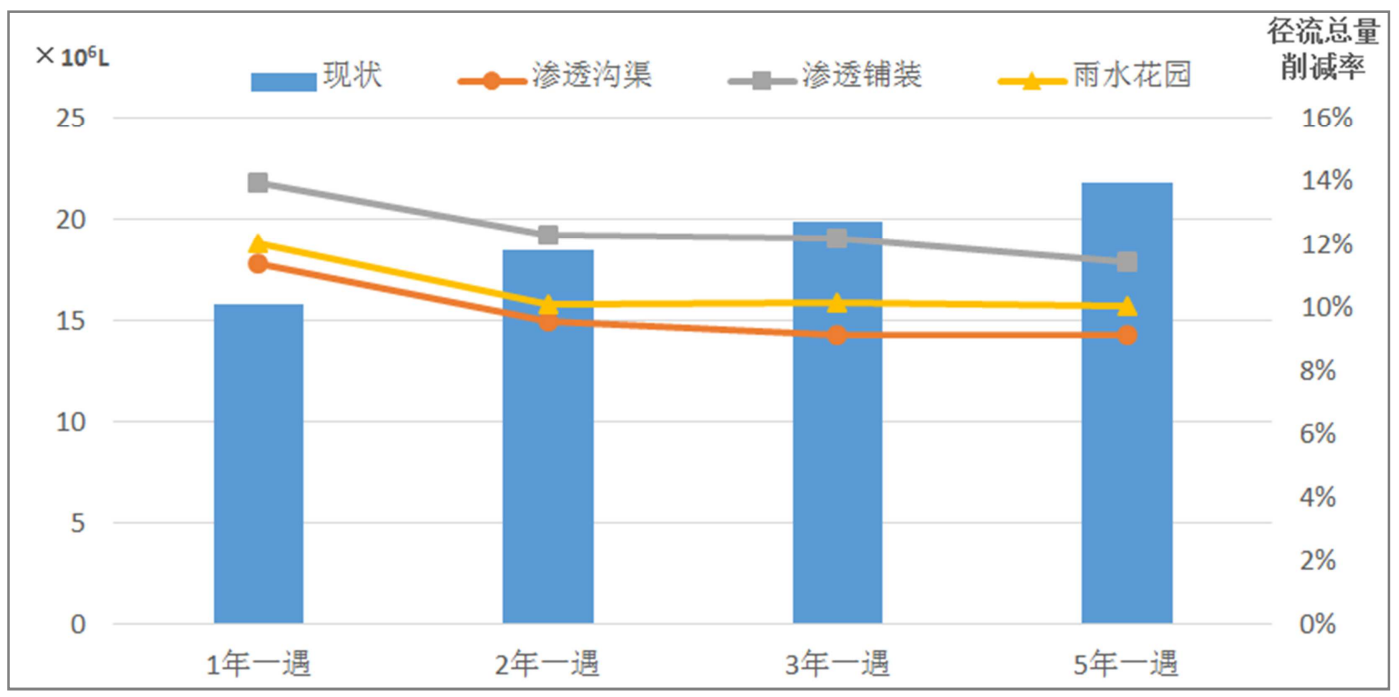

图7 排水口025径流总量控制分析图。 


\section{5. 结论}

（1）本文以海绵城市建设中径流总量控制和径流峰 值控制为目标, 确定研究区渗渠、透水铺装、雨水花园等 LID措施的参数和规模, 采用SWMM模型对研究区水文水力 特性进行概化, 建立了城市雨洪模型, 作为睢州市城区暴 雨径流模拟研究技术支撑。

(2) 使用SWMM模型中LID模块对三种低影响措施进行 模拟, 对研究区对城市洪涝防治和海绵城市建设具有一定 借鉴意义。通过对模拟结果进行积水控制和径流控制分析 发现, 渗透沟渠措施不仅对节点积水改善效果最好, 而且 对径流洪峰削减和延缓峰现时间作用最明显, 透水铺装措 施对排水口径流总量削减作用最强, 雨水花园措施对雨洪 控制效果介于两者之间。

\section{致谢}

本研究受中国浙江省水利厅科技项目”基于水文水动 力耦合模型的城市实时洪涝预警研究与应用”（项目编号 RB1501）、中国重点地区洪水风险图项目 “雎州市城市洪 水风险图”（项目编号CTZB-QZ201450011）资助。

\section{参考文献}

[1] Line D E. White N M. Effects of development on runoff and pollutant export. Water Environment Research. 2007, 79(2) : 185-190.

[2] 车伍, 赵杨, 李俊奇. 海绵城市建设热潮下的冷思 [J]. 南方 建筑, 2015, 4:104-107。
［3］王虹, 丁留谦, 李娜. 海绵城市建设的径流控制指标探析 [J] 中国防汛抗旱, 2015, 第3期: 10-15。

[4] 俞孔坚, 李迪华, 袁弘, 等. “海绵城市” 理论与实践 $[J]$. 城 市规划, 2015, 06期 (6) :26-36。

[5] 车伍, 赵杨, 李俊奇, 等. 海绵城市建设指南解读之基本概 念与综合目标 $[J]$. 中国给水排水，2015，30(8) : 1-5。

[6] Roy A H, Wenger S J, Fletcher T D, et al. Impediments and solutions to sustainable, watershed-scale urban storm water management: lessons from Australia and the United States. Environmental Management, 2008, $42(2)$ : 344-359

[7] Roseen R M, Ballestero T P, Houle J J, et al. Seasonal performance variations for storm-water management systems in cold climate conditions. Journal of Environmental Engineering: ASCE, 2009, $135(3)$ : 128-137.

［8］王雯雯, 赵智杰, 秦华鹏. 基于SWMM的低冲击开发模式水文 效应模拟评估 [J]. 北京大学学报: 自然科学版, 2012, 第2 期: 303-309。

[9］何爽, 刘俊, 朱嘉祺. 基于SWMM模型的低影响开发模式雨洪 控制利用效果模拟与评估 $[\mathrm{J}]$. 水电能源科学, 2013, 12 期: 42-45。

[10] 张涁, 戴贤波, 徐向阳, 等. SWMM模型在感潮河网城市排水防 涝计算中的应用 $[\mathrm{J}]$. 水电能源科学, 2014, 10期: 42-45。

[11] Lewis A Rossman. Storm Water Management Mode1 User' s Manual (version 5. 1) [M]. Wahington DC: USEPA, 2014.

[12] 岑国平, 沈晋, 范荣生. 城市设计暴雨雨型研究 [J]. 水科学 进展, 1998, 9(1):41-46。 